\title{
Врахування товщини листового матеріалу при виготовленні конічного диска згинанням плоского кільця
}

\author{
С.Ф. Пилипака ${ }^{1}$, Т.А. Кресан ${ }^{2}$, Т.П. Федорина ${ }^{3}$, В.І. Хропост ${ }^{4}$ \\ Національний університет біоресурсів і природокористування України \\ (м.Київ, Україна) ORCID ${ }^{1}$ 0000-0002-1496-4615; ${ }^{2}$ 0000-0002-8280-9502; \\ ${ }^{3}$ 0000-0001-9363-3955; ${ }^{4}$ 0000-0001-9363-3955
}

\begin{abstract}
При виготовленні деталей із листового матеріалу відбувається його деформація. Наприклад, ґрунтообробний диск конічної і сфреричної фооми мають різні робочі поверхні. У першому випадку поверхня є розгортною, у другому - нерозгортною. Згинання листового матеріалу у розгортну поверхню можна описати аналітично за допомогою відповідної теорії диференціальної геометрії. Вона ґрунтується на тому, що довжина ліній на поверхні і кути між лініями не змінюються в процесі згинання, а сама поверхня має нульову товщину. Ця теорія дає досить точні результати при згинанні листового матеріалу малої товщини, наприклад, листа паперу. Робочі органи, які несуть певне функціональне навантаження, повинні мати відповідну товщину матеріалу. Їх можна розглядати, як оболонку, обмежену внутрішньою і зовнішньою поверхнями. При згинанні такої оболонки теорія дає лише наближені результати.

В статті розглянута задача згинання плоскої заготовки заданої товщини у конічний диск. Заготовка у вигляді плоского кільця має гострий край зовнішньої периферії. Передбачається, що після згинання кільця у готовий виріб кут загострення зміниться. Потрібно знайти кут загострення заготовки, щоб після ії згинання конічний диск набув заданого кута загострення. Запропонована модель згинання ґрунтується на тому, що довжина загостреної крайки (леза) не змінюється під час згинання, а дві поверхні, що проходять через цю крайку, не змінюють своєї площі, тобто згинаються як поверхні нульової товщини. Розроблена математична модель, яка описує таке згинання. За отриманим аналітичним описом побудовано проміжні положення згинання обох поверхонь із спільною лінією перетину. Отримано формулу для знаходження кута загострення заготовки за заданим кутом загострення готового виробу. Згідно розробленої моделі товщина листа на готовому виробі буде меншою від товщини плоскої заготовки. Розроблена модель є однією із можливих при описанні процесу згинання листового матеріалу із врахуванням його товщини.
\end{abstract}

Ключові слова: плоске кільще; листовий матеріал; конічний диск; зәинання; деформація; кут загострення.

Постановка проблеми. Деякі деталі або робочі органи машин виготовляються згинанням листового матеріалу певної товщини. В диференціальній геометрії $€$ розділ, в якому розглянуто згинання поверхонь. Розроблено аналітичний апарат згинання, який ґрунтується на тому, що при згинанні поверхонь довжина ліній на них, кути між лініями та площа куска поверхні, яка згинається, не змінюються в процесі згинання. Однак цей апарат описує згинання поверхонь нульової товщини, яких на практиці не існує. При використанні тонкого листового матеріалу результати обчислень та побудови розгортки виробу будуть достатньо точними. При виготовленні виробів згинанням доволі товстого листового матеріалу цей факт потрібно враховувати. В статті розглянуто згинання плоского кільця у диск, який має форму зрізаного конуса. Такі диски можуть служити робочими органами сільськогосподарських машин для поверхневого обробітку ґрунту. Перифрерія диска має бути загострена під заданим кутом. В роботі ставиться задача знайти таку величину кута загос- трення на перисрерії плоского кільця, щоб після його згинання у готовий виріб, тобто після десормації кільця, цей кут набув заданої величини.

Аналіз останніх досліджень і публікацій. Теорія згинання поверхонь розглянута в монографріях [1, 2] та тримала подальший розвиток в працях із прикладної геометрії [3 - 6]. Застосування теорії до виготовлення робочих органів згинанням плоских заготовок здійснено в працях $[7,8]$. В зв'язку із тим, що листовий матеріал має товщину, то його можна розглядати, як оболонку, обмежену двома поверхнями. Крім того, матеріал листа чинить опір згинанню і схильний до часткового розгинання. Розрахунки за класичною теорією згинання в цьому випадку можуть дати наближені результати. В працях $[9,10]$ запропоновано підхід, який враховує названі фрактори.

Формулювання цілей та завдання статті. Здійснити аналітичний опис згинання плоского кільця із зовнішньою фаскою у конічний диск з оцінкою деформації кута загострення фраски. 
Основна частина. Плоске кільце із листового матеріалу товщиною а, у якого по зовнішньому колу радіуса $R$ знято фраску під кутом $\varepsilon$ (рис. $1, a)$, потрібно зігнути у конічний диск, прямолінійні твірні якого нахилені під заданим кутом $\beta_{\circ}$ до основи (рис. 1,б). Потрібно знайти такий радіус $R$ кільця і кут $\varepsilon$ фраски (або кут загострення), щоб після згинання вони набули заданих величин $R_{0}$ і $\varepsilon_{0}$. На рис. 1,б для наочності конічний диск зображено незамкненим.

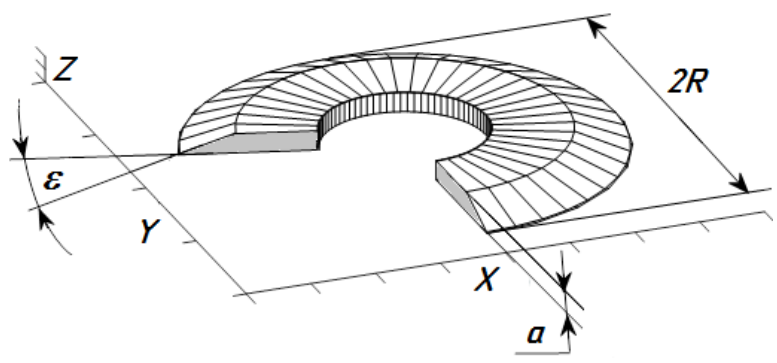

a

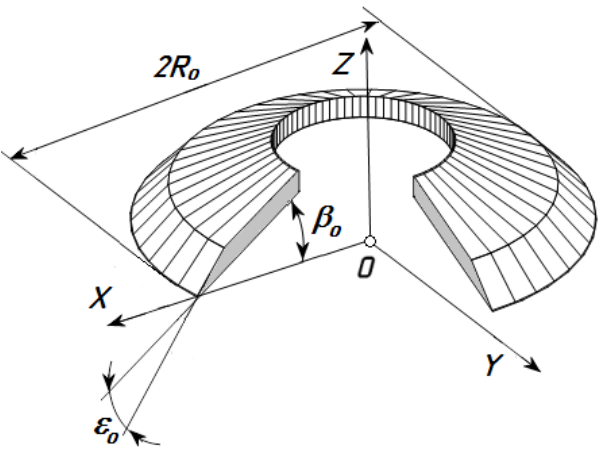

б

Рис. 1. Плоске кільце до і після згинання:

а) плоске кільце із знятою фаскою - заготовка для виготовлення диска;

б) конічний диск після згинання заготовки (умовно показаний незамкненим)

Загострена крайка диска (рис. 1,в) є лінією перетину двох конусів: у одного твірні нахилені до основи під кутом $\beta_{0}$, у другого - під кутом $\varphi_{0}=$ $\beta_{0}+\varepsilon_{0}$. Будемо виходити із припущення, що при згинанні заготовки площа цих двох конусів не змінюється і довжина лінії перетину (кола), теж не змінюється. Тепер розглянемо поступове згинання поверхні конуса нульової товщини з допомогою апарату диференціальної геометрії. Нехай буде задано конус, в який потрібно зігнути плоску заготовку (його розгортку) радіусом основи $R_{0}$ i кутом нахилу твірних $\beta_{\text {o }}$ (рис. 2,a).

В кожній точці кривої на поверхні $€$ певне значення кривини - величини, оберненої до радіуса кривини. За таку криву візьмемо основу конуса - коло радіуса $R_{0}$. Тоді кривина в усіх його точках буде сталою і рівною $k=1 / R_{0}$.

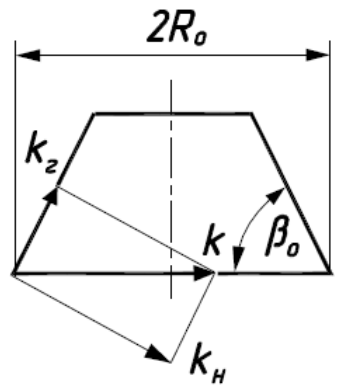

a

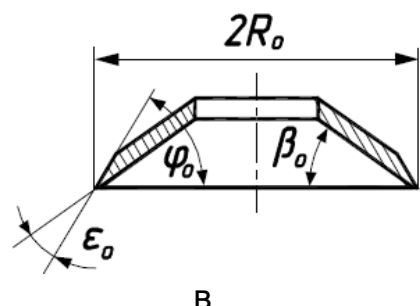

B

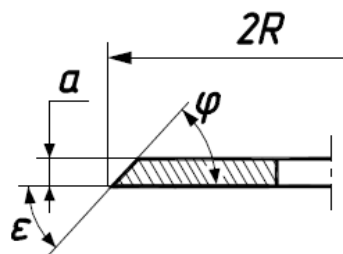

б

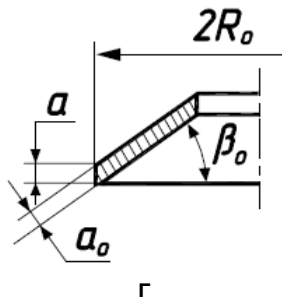

$\Gamma$
Рис. 2. Графрічні ілюстрації до згинання конуса: а) розкладання кривини основи на геодезичну і нормальну складові; б) геометричні параметри плоскої заготовки; в) геометричні параметри готового виробу; г) готовий виріб, зігнутий із заготовки без фраски

Кривину розглядають, як векторну величину, яка спрямована до центру кривини (в нашому випадку - до центра кола). Розкладемо ії в двох перпендикулярних напрямах - на дотичну площину і на нормаль до поверхні.

Одна складова носить назву геодезичної кривини $k_{\Gamma}=k \cdot \cos \beta_{0}$, а друга - нормальної кривини $k_{\mathrm{H}}=k \cdot \sin \beta_{0}$. Із диференціальної геометрії відомо [1], що при згинанні поверхні закономірність розподілу геодезичної кривини вздовж кривої не змінюється, а для нашого випадку буде сталою: $k_{\mathrm{r}}=k \cdot \cos \beta_{\mathrm{o}}=\cos \beta_{\mathrm{o}} / R_{\mathrm{o}}=$ const. В процесі згинання конуса величина його радіуса основи і кута нахилу твірних змінюватимуться, але в цілому їх добуток залишиться сталим. Поточні значення цих величин при згинанні позначимо без індексів, отже можна записати: $\cos \beta_{0} / R_{\mathrm{o}}=$ $\cos \beta / R$. Зокрема, при згинанні конуса на площину (знаходженні його розгортки) кут $\beta=0$, звідки знаходимо радіус зовнішнього кола розгортки: $R=R_{0} / \cos \beta_{0}$.

Запишемо параметричні рівняння конуса 3 радіусом основи $R_{\mathrm{o}}$ і кутом нахилу твірних $\beta_{0}$ :

$$
\begin{gathered}
X=\left(R_{0}-u \cos \beta_{0}\right) \cos \alpha_{0} ; \\
Y=\left(R_{0}-u \cos \beta_{0}\right) \sin \alpha_{0} ; \\
Z=u \sin \beta_{0},
\end{gathered}
$$

де $\alpha_{0}, u$ - незалежні змінні поверхні, причому $\alpha-$ кутова координата, яка відраховується від осі $O X$, $u$ - лінійна координата (довжина прямолінійної твірної від основи). 
Із рівності $\cos \beta_{\mathrm{o}} / R_{\mathrm{o}}=\cos \beta / R$ визначаємо, як змінюється радіус основи $R$ в залежності від зміни кута $\beta: R=R_{\mathrm{o}} \cdot \cos \beta / \cos \beta_{\mathrm{o}}$. Із рівності довжини дуги $s_{\mathrm{o}}=R_{\mathrm{o}} \cdot \alpha$ о до згинання і $s=R \alpha$ після згинання знаходимо:

$$
\alpha=R_{\mathrm{o}} \cdot \alpha_{\mathrm{o}} / R=\alpha_{\mathrm{o}} \cdot \cos \beta_{\mathrm{o}} / \cos \beta .
$$

Підставимо в рівняння (1) замість початкових величин $R_{\mathrm{o}}$ і $\alpha_{0}$ нові знайдені вирази $R$ і $\alpha$, а також замість $\beta_{\text {о }}$ - нове значення $\beta$ і отримаємо рівняння множини згинань вихідного конуса:

$$
\begin{gathered}
X=\left(R \frac{\cos \beta}{\cos \beta_{0}}-u \cos \beta\right) \cos \left(\frac{\cos \beta_{0}}{\cos \beta} \alpha_{0}\right) ; \\
Y=\left(R \frac{\cos \beta}{\cos \beta_{0}}-u \cos \beta\right) \sin \left(\frac{\cos \beta_{0}}{\cos \beta} \alpha_{0}\right) ; \\
Z=u \sin \beta .
\end{gathered}
$$

Вираз першої квадратичної форми рівнянь (2) не залежить від кута $\beta$. Це підтверджує те, що рівняння (2) справді $€$ рівняннями згинання конуса. При $\beta=\beta_{\text {о }}$ рівняння (2) перетворюються в рівняння (1), тобто описують вихідний конус, а при $\beta=0$ - описують розгортку.

Тепер будемо згинати два конуси із спільною лінією перетину - ріжучою крайкою. Згинання вихідного конуса описуються рівняннями (2). При зменшенні кута $\beta$ поверхня конуса наближатиметься до розгортки і стане нею при $\beta=0$. Кут $\varphi_{\text {о }}$ теж зменшиться до поточного значення $\varphi$. Оскільки два конуси будуть згинатися і при цьому лінія їх перетину буде спільною, то конкретному значенню кута $\beta$ буде відповідати певне значення кута $\varphi$, тобто $\varphi=\varphi(\beta)$. Наприклад, при $\beta=0$ кут $\varphi$ набуде значення, під яким потрібно зняти фаску (рис. 2,б). Знайдемо залежність $\varphi=\varphi(\beta)$.

Раніше нами отримана залежність між кутом нахилу твірних $\beta$ і радіусом ріжучої крайки $R$ : $\cos \beta_{\mathrm{o}} / R_{\mathrm{o}}=\cos \beta / R$. Ця залежність лежить в основі згинання конуса. Очевидно, що аналогічна залежність описує згинання другого конуса, утвореного фаскою, але при цьому в ролі кутів $\beta_{\text {о }}$ і $\beta$

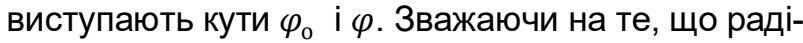
уси $R_{\text {o }}$ і $R$ спільні, для другого конуса запишемо: $\cos \varphi_{\mathrm{o}} / R_{0}=\cos \varphi / R$. Але $\varphi_{\mathrm{o}}=\beta_{\mathrm{o}}+\varepsilon_{0}$. Із врахуванням цього знайдемо значення $R=R_{0} \cos \beta / \cos \beta_{\mathrm{o}}$ із першого виразу, підставимо в другий i розв'яжемо відносно $\cos \beta$ :

$$
\cos \phi=\frac{\cos \beta \cos \left(\beta_{0}+\varepsilon_{0}\right)}{\cos \beta_{0}} .
$$

При $\beta=0$ із (3) можна знайти величину кута $\varphi$, під яким потрібно зняти фраску на плоскому кільці (рис. 2,б). Наприклад, на готовому диску із кутом нахилу твірних $\beta_{0}=20^{\circ}$ потрібно забезпечити кут загострення $\varepsilon_{0}=20^{\circ}$. При $\beta=0$ із (3) знаходимо: $\varphi=35^{\circ}$. Отже, згідно запропонованої моделі, при згинанні плоскої заготовки у готовий виріб кут загострення зменшуватиметься від $35^{\circ}$ до $20^{\circ}$. Проміжні положення кута загострення можна знайти із залежності (3) при зміні кута $\beta$ від нуля до $\beta_{0}$. Проміжні положення конуса фаски можна побудувати за рівняннями (2), підставивши в них замість кута $\beta$ перед змінною $u$ кут $\varphi$ із (3). Після цього отримаємо рівняння множини положень конуса фраски при його згинанні:

$$
\begin{gathered}
X=\left(R \frac{\cos \beta}{\cos \beta_{0}}-u \frac{\cos \beta \cos \left(\beta_{0}+\varepsilon_{0}\right)}{\cos \beta_{0}}\right) \times \\
\quad \times \cos \left(\frac{\cos \beta_{0}}{\cos \beta} \alpha_{0}\right) ; \\
Y=\left(R \frac{\cos \beta}{\cos \beta_{0}}-u \frac{\cos \beta \cos \left(\beta_{0}+\varepsilon_{0}\right)}{\cos \beta_{0}}\right) \times \\
\quad \times \sin \left(\frac{\cos \beta_{0}}{\cos \beta} \alpha_{0}\right) ; \\
Z=u \sqrt{1-\frac{\cos ^{2} \beta \cos ^{2}\left(\beta_{0}+\varepsilon_{0}\right)}{\cos ^{2} \beta_{0}}} .
\end{gathered}
$$

Окремі положення конуса фаски при згинанні заготовки отримаємо із (4) при значеннях

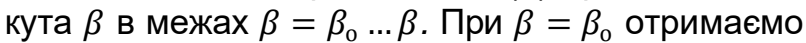
поверхню фаски на готовому виробі (диску), а при $\beta=0$ - поверхню фаски на плоскій заготовці. При інших значеннях кута $\beta$ будемо отримувати проміжні значення поверхні фаски.

На рис. 3 побудовані окремі положення обох конусів за рівняннями (2) і (4) для проміжних значень кута $\beta$ нахилу твірних. Для більшої наочності поверхні диска і фаски на готовому виробі (рис. 3,a) побудовано на три четверті, тобто при $\alpha_{\text {о }}=0 \ldots 1,5 \pi$. При згинанні основного конуса на площину цей кут дещо зменшується, а радіус спільного кола обох поверхонь зростає (рис. 3,б,в).

Якщо згинати плоску заготовку без фаски, тобто при $\varphi=90^{\circ}$ (рис. 2,б), то згідно формули (3) отримаємо: $\varepsilon_{0}=90^{\circ}-\beta_{0}$. Отже, якщо зігнути плоску заготовку без фаски у конус із кутом нахилу твірних $\beta_{\text {о }}=20^{\circ}$, то на готовому виробі з'явиться кут загострення $\varepsilon_{0}=70^{\circ}$. При цьому циліндрична поверхня висотою а на заготовці перейде у циліндричну поверхню такої ж висоти на конічному диску (рис. 2,б,г).

У розробленій моделі згинання плоскої заготовки у конічний диск висунуто припущення, що площа поверхонь не змінюється. Але при цьому змінюється кут загострення і товщина листа, 3 якого формується виріб. Із рис. 2,г, на якому зображено виріб, зігнутий із плоского кільця без фаски, можна визначити товщину листа після деформації: $a_{\mathrm{o}}=a^{\cos } \beta_{\mathrm{o}}$.

Висновки. Моделі згинання листового матеріалу нульової товщини у поверхню заданої формі базуються на теорії диференціальної геометрії. 


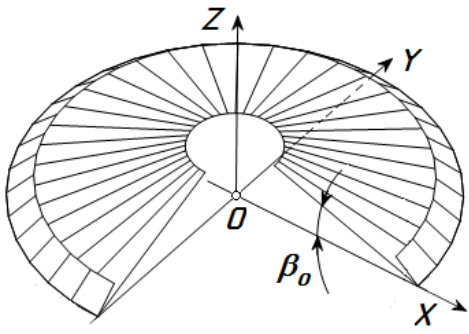

a

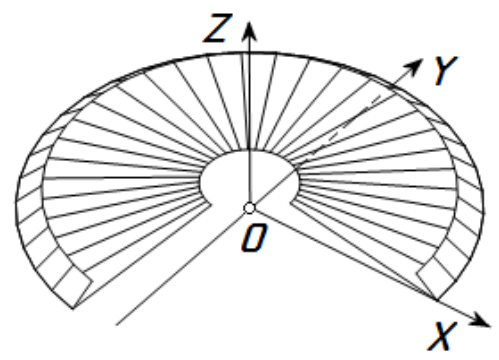

б

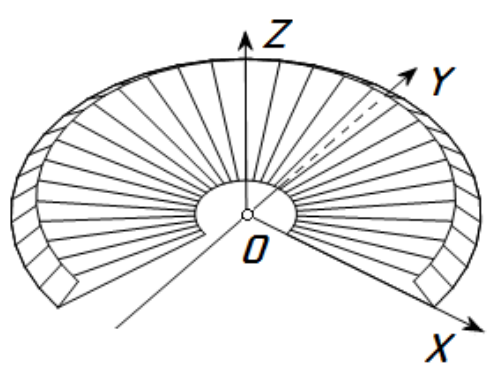

B

Рис. 3. Сумісне згинання двох конусів із спільною лінією перетину при $R=0,6 \mathrm{M}, \beta_{\mathrm{o}}=20^{\circ}$, $\varepsilon_{\mathrm{o}}=20^{\circ}$ : a) $\beta_{\mathrm{o}}=\beta=20^{\circ}$; б) $\beta=10^{\circ}$; в) $\beta=0^{\circ}$

Вони дають точні результати, однак не враховують товщини листового матеріалу. Розроблена модель згинання плоского кільця заданої товщини у конічну поверхню ґрунтується на тому, що поверхні, які обмежують кільце, не змінюють своєї площі в процесі згинання. В результаті певної деформації листового матеріалу змінюється його товщина.

\section{Література:}

1. Фиников С.П. Изгибание на главном основании. Москва, 1937. 176 с.

2. Петерсон К.М. Об изгибании поверхностей. Москва, 1952. Вып.5. С. 134-164.

3. Григорьев В.А. Некоторые геометрические вопросы изгибания винтовых поверхностей. КUнематические методы конструирования технических поверхностей. Труды МАИ. Москва, 1973. Вып.270. С. 40-44.

4. Мокрушина А.Т. Изгибание геликоидов. Прикладные задачи геометрических преобразований. Кишинев, 1977. С. 8-11.
5. Пилипака С.Ф. Неперервне згинання косого гелікоїда в однопорожнинний гіперболоїд обертання. Прикладна геометрія та інженерна графріка. 1996. Вип. 61. С. 140-144.

6. Кресан Т.А., Пилипака С.Ф., Несвідомін А.В., Бабка В.М., Кремець Я.С. Згинання однопорожнинного гіперболоїда обертання зміною радіуса горлової лінії. Сучасні проблеми моделювання: зб. наук. праць / МДПУ ім. Б. Хмельницького. Мелітополь, 2020. № 17.С. 36 - 46.

7. Пилипака С.Ф. Практичні аспекти гнуття шнеків сільськогосподарських машин. Збірник наукових праць Національного аграрного угіверситету "Механізація сільськогосподарського виробниитва". -Том 6. "Теорія і розрахунок сільськогосподарських машин". Київ, 1999. С.149-51.

8. Пилипака С.Ф., Несвідомін В.М., Пилипака Т.С., Хмеленко О.С. Розрахунок заготовки для виготовлення гвинтової поверхні котка. Електротехніка і механіка. Київ, 2008. № 1. С. 71-77.

9. Пилипака С.Ф., Несвідомін В.М., Пилипака Т.C. Визначення фріктивного контуру деталі при згинанні листового матеріалу в циліндричну поверхню заданої форми із врахуванням пружинення металу. Праці Таврійської державної агротехнічної академії. Вип. 4. Прикл. геометрія та інж. графріка. Том 30. Мелітополь, 2005. С. 67-73.

10. Пилипака С.Ф., Несвідомін В.М., Пилипака Т.С. Згинання конічних поверхонь із листового матеріалу із врахуванням пружинення металу. Збірник наукових праць Київського національного університету технологій та дизайну (спецвипуск). Київ, 2005. С. 159-162.

\section{References:}

1. Finikov, SP 1937, Bending on the main base, ONTI, Moscow.

2. Peterson, KM 1952, About the bending of surfaces, IMI, Moscow.

3. Grigor'ev, VA 1973, 'Some geometric questions of bending of helical surfaces', Kinematic methods for designing technical surfaces. Proceedings of the MAI,. Vol. 270, pp. 40-44.

4. Mokrushina, AT 1977, 'Bending of helicoids', Applied problems of geometric transformations, pp 8-11.

5. Pylypaka, SF 1996, 'Continuous bending of the oblique helicoid into a single-cavity hyperboloid of rotation', Applied geometry and engineering graphics, Vol. 61, pp. 140-144.

6. Kresan, TA, Pylypaka, SF, Nesvidomin, AV, Babka, VM, Kremets, YaS 2020 'Bending of a singlecavity hyperboloid of rotation by changing the radius of the throat line', Modern problems of modeling: coll. Science. Works. MDPU them. B. Khmelnytsky, № 17 , pp. 36 - 46.

7. Pylypaka ,SF 1999, 'Practical aspects of bending augers of agricultural machines', Collection 
of scientific works of the National Agrarian University "Mechanization of agricultural production", Vol. 6. "Theory and calculation of agricultural machinery", pp.149-51.

8. Pylypaka, SF, Nesvidomin. VM, Pylypaka. TS, Khmelenko, OS 2008, 'Calculation of the workpiece for the manufacture of the helical surface of the roller', Electrical engineering and mechanics, № 1, pp. 71-77.

9. Pylypaka, SF, Nesvidomin, VM, Pylypaka, TS 2005, 'Determination of a fictitious contour of a detail at bending of sheet material in a cylindrical surface of the set form taking into account springing of metal', Proceedings of the Tavriya State Agrotechnical Academ. App. geometry, etc. Graphics, Vol. 30, pp. 67-73.

10. Pylypaka, SF, Nesvidomin,VM, Pylypaka, TS 2005, 'Bending of conical surfaces from sheet material taking into account spring of metal', Collection of scientific works of Kyiv National University of Technology and Design (special issue). pp. 159-162.

Аннотация

\title{
Учет толщины листового материала при изготовлении конического диска сгибанием плоского кольца
}

\author{
С.Ф. Пилипака, Т.А. Кресан, Т.П. Федорина, В.И. Хропост
}

При изготовлении деталей из листового материала происходит его деформация. Например, почвообрабатывающий диск конической и сферической формы имеют различные рабочие поверхности. В первом случае поверхность является развертывающейся, во втором - неразвертывающейся. Изгибание листового материала в развертывающуюся поверхность можно описать аналитически с помощью соответствующей теории дифференциальной геометрии. Она основывается на том, что длина линий на поверхности и углы между линиями не меняются в процессе изгибания, а сама поверхность имеет нулевую толщину. Эта теория дает достаточно точные результаты при изгибании листового материала малой толщины, например, листа бумаги. Рабочие органы, которые несут определенную функциональную нагрузку, должны иметь соответствующую толщину материала. Их можно рассматривать как оболочку, ограниченную внутренней и внешней поверхностями. При изгибании такой оболочки теория дает лишь приближенные результаты.

В статье рассмотрена задача изгибания плоской заготовки заданной толщины в конический диск. Заготовка в виде плоского кольца имеет острый край внешней периферии. Предполагается, что после изгибания кольца в готовое изделие угол заострения изменится. Нужно найти угол заострения заготовки, чтобы после ее изгибания конический диск получил заданный угол заострения. Предложенная модель изгибания основывается на том, что длина заостренной кромки (лезвия) не изменяется во время изгибания, а две поверхности, проходящие через эту кромку, не изменяют своей площади, то есть изгибаются как поверхности нулевой толщины. Разработана математическая модель, описывающая такое изгибание. По полученному аналитическому описанию построены промежуточные положения изгибания обеих поверхностей с общей линией сечения. Получена формула для нахождения угла заострения заготовки по заданному углу заострения готового изделия. Согласно разработанной модели толщина листа на готовом изделии будет меньше толщины плоской заготовки. Разработанная модель является одной из возможных при описании процесса изгибания листового материала с учетом его толщины.

Ключевые слова: плоское кольцо; листовой материал; конический диск; изгибание; деформация; угол заострения.

Abstract

\section{Taking into account the thickness of the sheet material in the manufacture of a conical disk by bending a flat ring}

\section{S.F. Pylypaka, T.A. Kresan, T.P. Fedoryna, S.I. Hropost}

In the manufacture of parts from sheet material is its deformation. For example, conical and spherical tillage discs have different working surfaces. In the first case, the surface is developable, in the second nondevelopable. The bending of the sheet material into the unfolding surface can be described analytically using the appropriate theory of differential geometry. It is based on the fact that the length of the lines on the surface and the angles between the lines do not change during bending, and the surface itself has zero thickness. This theory gives fairly accurate results when bending sheet material of small thickness, such as a sheet of paper. Working bodies that carry a certain functional load must have the appropriate thickness of the 
material. They can be considered as a shell bounded by inner and outer surfaces. When bending such a shell, the theory gives only approximate results.

The problem of bending a flat workpiece of a given thickness into a conical disk is considered in the article. The workpiece in the form of a flat ring has a sharp edge of the outer periphery. It is assumed that after bending the ring into the finished product, the sharpening angle will change. It is necessary to find the angle of sharpening of the workpiece, so that after bending the conical disk acquired a given angle of sharpening. The proposed model of bending is based on the fact that the length of the pointed edge (blade) does not change during bending, and the two surfaces passing through this edge do not change their area, ie they bend as surfaces of zero thickness. A mathematical model describing such bending has been developed. According to the obtained analytical description, the intermediate bending positions of both surfaces with a common line of intersection are constructed. The formula for finding the angle of sharpening of the workpiece for a given angle of sharpening of the finished product is obtained. According to the developed model, the thickness of the sheet on the finished product will be less than the thickness of the flat workpiece. The developed model is one of the possible ones when describing the process of bending sheet material taking into account its thickness.

Keywords: flat ring; sheet material; conical disk; bending; deformation; sharpening angle.

\section{Бібліографічне посилання/ Bibliography citation: Harvard}

Pylypaka, S. F. et al. (2020) 'Taking into account the thickness of the sheet material in the manufacture of a conical disk by bending a flat ring', Engineering of nature management, (2(16), pp. 78 - 83.

Подано до редакції / Received: 12.08.2020 